\title{
The Practical Exploration of the Teaching Mode of Subjective Open Dynamic System
}

\author{
Suting Zhang \\ NanChang Institute of Science \& Technology,Nanchang,330108
}

Keyword: Students; Class teaching; Open teaching.

\begin{abstract}
How to play the role of class, to simulate students' interest to achieve the get the effect as we can, has become the puzzling problem that every educator needs to find solutions to solve. This paper explores the realistic situation and class teaching of school students. Firstly, start the investigation from the reality of students and condition, and expounds the necessity of implementing open classroom teaching in schools. And, expounds the theoretical basis and teaching principle of implementing open classroom teaching. Then explores the open teaching process in class and make research on the teaching experimental study of this model and the experimental results areanalyzed and discussed. Connect teaching and realistic student's real life, lead the open teaching mode into the class teaching in secondary school to develop the innovative spirits and practical ability of students, improve their literacy and aesthetic taste, adapt the needs of order-base and sustainable development of human beings and the requirements convergence with international education and qualification certificates.
\end{abstract}

\section{Introduction}

The goal of education is to cultivate practical talents with comprehensive ability and overall quality for the first line of production and service. The traditional teaching regards book as the base and teacher a $\mathrm{s}$ the center, comprehends the teaching process as a special cognition process, focuses too much on the indirectness, conciseness and guidance of the teaching process that neglects the experience, process and autonomy of teaching process. Too much arc mastery of knowledge in teaching process and general acceptance of knowledge of and common sense, but ignore the individual emotion, experience, understanding, imagination and other psychological processes, and also the self-demand that students should have. How to play the role of class, to simulate students' interest to achieve the get the effect as we can, has become the puzzling problem that every educator needs to find solutions to solve. This paper explores the realistic situation and class teaching of school students. Firstly, start the investigation from the reality of students and condition, and expounds the necessity of implementing open classroom teaching in schools. And, expounds the theoretical basis and teaching principle of implementing open classroom teaching. Then explores the open teaching process in class and make research on the teaching experimental study of this model and the experimental results are analyzed and discussed.

\section{Teaching Status}

School education has always been in the trap of education. Between the education processes, which are elementary education stage and higher educationstage. It's not as spectacular as the education in basic stage nor as superior university education in higher education, and with a nondescript irregularity and weak social identity. The condition continues until today, and with the following characteristics:

Emphasize inheritance in teaching philosophy, and ignore innovation. Influenced and dominated by the traditional concept of "education" for a long time. Teachers are accustomed to the mode of grant and receive. Regard knowledge, teacher and book as the main part and turn the lively teaching into the one-way instillation of knowledge. For completing the teaching mission, lots of teachers generally focus on the instilling of knowledge, but they've neglected the student's ability of analyzing and solving problems, the improvement of their ideological consciousness and the cultivation of their creative thinking ability and individual development needs, which has weakened their flexibility and tension, and cut the space for innovative thinking. 
Teachers pay too much attention on the knowledge in classes but disregard extracurricular and social knowledge. Professional courses focus on practice and internship, but cultural classes are mostly carried out in classroom. Teachers just read the books and teach fully depend on books, which is lack of creativity and inspiration. The acceptance of knowledge has almost become the only activity in class and class teaching is almost the only form.

\section{Principle of Open Class Teaching}

Open class teaching aims at the disadvantages of current class teaching. It no longer regards students as a whole, nor deliberately establishes teacher's authority in class. Instead, the initiative of learning will be given back to students. Learning process, content and time are controlled by students, which can fully play the subjective initiative of student's autonomous learning, and also offer individualized learning mechanism to students. This kind of open class requires breaking the closure of class time by allowing the time in and out of class to connect together naturally, to let the classroom becomes the place for students to relax, learn, communicate and research freely. In addition, the space outside the classroom become the learning space requires to break down the disclosure of teaching content. Let content of social life and natural life into the class requires breaking the shackles of class to student's thinking. Allowing students to fully operationalize their thinking requires breaking the class suppression to student's personality, so that students would get free personality and so on. All these changes aim at trying to break the current boring and closed status of class, to enable students to break the exam-oriented education and letting learning offer service for student's development. Today's international education community has already regards the open education as an important strategy for education reform. As a subsystem of education system, and combined with the characteristics of the discipline itself, class teaching should be an all-round open system.

\section{The Basic Characteristics of Open Teaching Mode}

Open of Teaching Ideas. The traditional teaching idea regards knowledge as the center, it focuses too much on the imparting of knowledge, and ignores the experience process; Regard subjects as the center and ignore the education of holistic knowledge; Focus on developing intelligence and ignore the training of emotion, attitude and values. Open teaching ideology embodies the idea of quality education and human development as the primary goal.

Open of Teaching Content. The core of the new curriculum reform is to cultivate students' innovative spirit and practice ability, so teachers should creatively deal with teaching materials. Teachers should not treat the teaching content as solidified, but should also combine with the cognitive rules of students, their own knowledge and life experience. Pay attention to connect the actual teaching and students together, collect information to expand or replace part of the teaching material to make the teaching content more vivid.

Open of Teaching Process. The traditional teaching process reflects the "injection type" or "cramming type", which is mainly based on teacher. Students mainly use memory or storage, lack of the opportunities of independent thinking, digestion and absorption that has limited student's creative thinking and depressed student's initiative and create potential.

Open of Teaching Space. Let students learn in the vast social environment. Actually, all these open teaching methods have their own theoretical basis. Constructivism considers that the best way for learners to complete the construction of the meanings of knowledge is to let them feel and experience in the real environment of the real world instead of listening to others' introduction and explanation about such experience. 


\section{Teaching Process of Open Class}

Based on the reality of students and the structural process of the real open class is:

Create situation, simulate motivation and promote perception

Teachers create situation based on their own learning goals, and create an atmosphere in which students can experience "real-time" personal experience, on-the-spot experience and their feelings. Students can be effectively trained only in this kind of situation. This is the beginning of teaching, but also the orientation of learning activities.

Active participation, active experience and bold attempt

Students autonomously can get more things such as learning methods, exploration spirit, self-confidence and so on, besides the required knowledge and skills. Even in terms of prescribed knowledge and skills, its long-term persistence, intrinsic motivation and effective usability are much higher than the former.

Cooperation and communication, deepen understanding and improve merit

In the individual learning activities of students, due to the effects of learning base, learning habits, life experiences, intellectual differences and other factors, the effects of each student's learning and their learning strategies have merit. Cooperation is one of the issues of great concern in class teaching, which can reflect the modern teaching ideas.

\section{Conclusion}

As the basic discipline, curriculum assumes the task of inheriting the national traditional culture and improving the overall qualities of students, and lays the foundation for improving student's comprehensive ability and the ability to adopt changes. Reforming the teaching mode connects teaching and student's real life; Lead the open teaching mode into class teaching of secondary school to develop student's innovative spirit and practical ability of language and enhance their quality and aesthetic taste, so that they can adapt to the needs of order-based training, sustainable development of human beings, the requirements of convergence with international education and qualification certificates, and also provide an effective way for the implementation of the current new curriculum reform. Teaching is a dynamic and open system. The opening class teaching mode based on the reality of school students and the real open class teaching mode is guided by the concept of new curriculum reform. It's constructed on the base of constructivism theory and subject education theory with the concept of "large education". It deeply explores the class teaching system and evaluation system and makes the whole teaching system in the best control state, thus form a new teaching system.

\section{References}

[1] Liu G, Liu L, Cao J. Practice and Exploration of the Graded Teaching of Higher Mathematics[J]. Journal of Hunan Institute of Engineering, 2017.

[2] Liu L. Problems and Discussion in Higher Mathematics Teaching[J]. Journal of Changsha Medical University, 2015.

[3] Wang X B. A Study on the Construction of the Flipped Classroom Teaching Model of Higher Mathematics in the Newly-Built University[J]. Journal of Anqing Teachers College, 2016.

[4] Fan J H, Yao A L. On the Teaching Problems and Countermeasures of Higher Mathematics in Higher Vocational Colleges[J]. Contemporary Continuing Education, 2016.

[5] Wang K S. Higher Mathematics in Mathematical Modeling Thought in Higher Vocational Undergraduate Teaching[J]. Journal of Hubei Correspondence University, 2016.

[6] Hai-Yan W U. Higher mathematics course teaching method of colleges in transformation period[J]. Heilongjiang Science, 2016. 
[7] Liu M X, Liu Y J, Jiang X Z. Exploration on the Cooperation Teaching in Higher Mathematics[J]. Journal of Yulin Normal University, 2015.

[8] Lin Y, Mathematics D O, University J. Error analysis of higher mathematics exercises and teaching countermeasures[J]. Journal of Science of Teachers College \& University, 2015.

[9] Dong J H,Geng X R. The Variant Thinking during Example Teaching of Multi-solution Questions in Higher Mathematics[J]. Journal of Guizhou University of Engineering Science, 2016.

[10]Zhao H X, Rong J H, Lin X Q. The Investigation of Teaching Mode for Higher Mathematics volume One[J]. Science \& Technology Vision, 2016.

[11] Tang F Q, Cui-Zhen D U. Notes in the Teaching of Higher Mathematics[J]. Journal of Huaibei Normal University, 2015.

[12]Zhu J B. The Effective Integration of Mathematics Culture in Higher Vocational Mathematics Teaching $[\mathrm{J}]$. Journal of Hubei Correspondence University, 2016. 